\title{
Contribuições do Geoprocessamento para estudos de risco e vulnerabilidade socioambiental em Natal/RN, Brasil
}

Geoprocessing contributions for risk and socio-environmental vulnerability studies in Natal / RN, Brazil

MACEDO $^{1}$, Y. M.

yurimmacedo@hotmail.com;

\begin{abstract}
Resumo
O Geoprocessamento é uma ferramenta muito utilizada e fundamental aos estudos de risco de desastre e/ou vulnerabilidade socioambiental dentro da Ciência geográfica. Estes estudos visam caracterizar, analisar e mapear o risco presente em determinado território. O qual é uma função entre a vulnerabilidade social e os perigos naturais. Deste modo, o geoprocessamento incide fundamentalmente no mapeamento, sobreposição e análise de dados georreferenciados nesta temática. Este artigo consiste no relacionamento entre essas duas áreas do conhecimento geográfico, com ênfase em seus pressupostos teórico-metodológicos. Utilizando-se, como estudo de caso, dois trabalhos realizados em Natal, RN - Brasil. Com escala do próprio município; e outro com escala de detalhe, do bairro Mãe Luiza, marcado por eventos de desastre com grande prejuízo financeiro e até de perda humana associada.
\end{abstract}

Palavras-Chave: Vulnerabilidade; Risco; Geoprocessamento

\begin{abstract}
The geoprocessing is a tool widely used and essential for risk assessments of disaster and/or environmental vulnerability within the geographical science. These studies aim to characterize, analyze and map the risks present in a given territory. Which is a function between social vulnerability and natural hazards. Thus, the geoprocessing focuses primarily on mapping, overlaying and georeferenced data analysis of this subject. This paper is the relation between these two areas of geographical knowledge, with emphasis on their theoretical and methodological assumptions. Using, as a case study, two papers conducted in Natal, RN - Brazil. One with a municipal scale level; and another with detail scale, in the Mãe Luiza district, marked by disaster events with great financial and human loss.
\end{abstract}

Key words: Vulnerability; Risk; Geoprocessing

\section{INTRODUÇÃO}

Este trabalho tem como objeto analisar como o geoprocessamento é uma ferramenta indispensável aos estudos de risco em Geografia, trazendo dois trabalhos realizados em Natal, capital do Estado do Rio Grande do Norte, como estudos de caso que comprovam a eficácia dessa utilização, evidenciando sua concepção teórico-metodológica, operacionalização e resultados obtidos.

Estas características são relacionadas e permeiam as análises de risco e vulnerabilidade em Geografia, em que se faz necessário analisar variáveis sociais e ambientais para definição de quais áreas são vulneráveis ao processo socioambiental, passível de causar danos à vida ou prejuízos 
materiais. O geoprocessamento, e as técnicas de cartografia digital são fundamentais para estas análises e seu mapeamento pelo território em estudo. A partir destas ferramentas, o pesquisador agrupa seus dados coletados, sobrepõem variáveis e faz as análises espaciais que têm como produto os mapas de risco, por exemplo.

Outro exemplo de aplicabilidade do Geoprocessamento para a temática dos estudos de risco é a construção e modelagem de banco de dados em ambiente SIG - Sistema de Informações Geográficas, onde se podem obter informações georreferenciadas muito importantes para o planejamento urbano e ambiental. Algumas práticas utilizando estas ferramentas são: saber quais bairros ou distritos têm mais variáveis características de vulnerabilidade social e quais são estas variáveis; quais zonas ou regiões da cidade são mais suscetíveis e/ou estão mais expostas a eventos de desastres; a que processos naturais perigos estas áreas estão expostas; quais locais há maior risco, ou seja, tem que se ter ações imediatas.

Com o auxílio de softwares computacionais modernos com rápido processamento de dados georreferenciados em SIG, estas perguntas podem ser respondidas prontamente, gerando produtos como mapas e arquivos digitais de feições com banco de dados associados (as camadas ou layers). Portanto, fazem-se fundamentais ao mapeamento e análises espaciais inerentes aos estudos de risco de desastre socioambiental, em que o pesquisador tem a necessidade básica de dominá-las. Pode-se realizar este tipo de estudo sem estas ferramentas, porém a qualidade e organização dos dados ou produtos não seriam tão satisfatórios e precisos quanto com uso do geoprocessamento. A figura 01 delineia o recorte espacial da área de estudo para este artigo, que se trata da capital potiguar no primeiro trabalho utilizado como estudo de caso, e o bairro de Mãe Luiza no segundo trabalho analisado. 


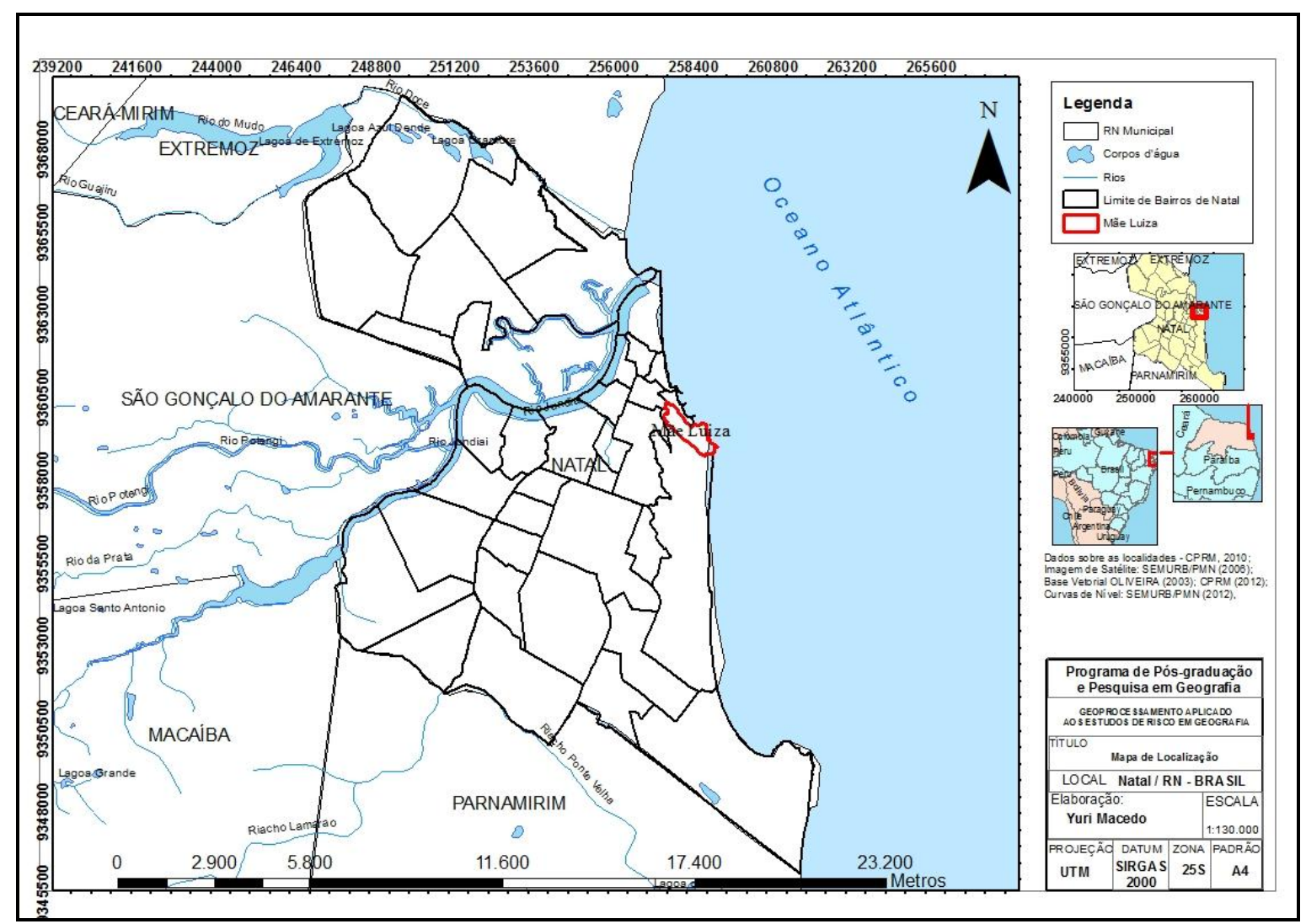

Figura 01. Mapa de localização de Natal e Bairro Mãe Luiza. Elaboração: Yuri M. Macedo (2016).

Assim, foi definido como objetivo geral deste trabalho analisar o geoprocessamento enquanto ferramenta fundamental aos estudos de risco em Geografia, utilizando dois trabalhos sobre vulnerabilidade socioambiental no município de Natal, como estudos de caso sobre a utilização desta ferramenta para compreensão das inter-relações entre vulnerabilidade social e exposição aos perigos naturais. Deste modo foi possível, especificamente: a) evidenciar os pressupostos teórico-metodológicos que fundamentam os estudos de risco em Geografia, assim como os que estruturam o Geoprocessamento e a cartografia digital. b) observar na prática, a partir de dois estudos com diferentes escalas sobre a temática do risco socioambiental, como o geoprocessamento é uma ferramenta fundamental a estes estudos. c) analisar os principais produtos e correlações que podem ser estabelecidas com utilização do geoprocessamento.

\section{REFERENCIAL TEÓRICO-METODOLÓGICO}

Estudos de Risco em Geografia

Será posta à luz desta discussão a abordagem Geossistêmica, inicialmente formulada por Sotchava e em seguida desenvolvida por Bertrand tendo em vista que este último trouxe uma divisão taxonômica da paisagem mais precisa e próxima à escala socioeconômica. Esta referência é 
base para os estudos de Geografia Física em geral, em que estão inseridos os estudos de risco em Geografia, o qual precisa ser identificado no arcabouço teórico deste trabalho.

\begin{abstract}
Numa tentativa de síntese da paisagem, Bertrand estabelece um sistema taxonômico para o geossistema, possibilitando sua classificação em função da escala, caracterizando-o como uma unidade, um nível taxonômico na categorização da paisagem, a saber: a zona, o domínio e a região, como unidades superiores, e o geossistema, o geofácies e o geótopo, como unidades inferiores; sendo o geossistema proporcionado pela dinâmica entre potencial ecológico, exploração biológica e ação antrópica. Isto permite situá-lo na dupla perspectiva do tempo e do espaço, fundamentais ao geógrafo. (NASCIMENTO; SAMPAIO, 2004/2005 p.169).
\end{abstract}

A abordagem geossistêmica subsidia a Geografia Física, pois a mesma oferece uma metodologia mais coerente, possibilitando os estudos integrados da paisagem sem deixar de fazer a correlação entre os seus subsistemas naturais e as interferências socioeconômicas. Como colocado por Nascimento e Sampaio (2004, p. 170), "os geossistemas constituem uma boa base aos estudos geográficos por estarem numa escala compatível à humana”. Tricart chama atenção que a concepção de geossistemas elaborada por Bertrand "distingue tres niveles sucesivos: elmedio físico, loseco-sistemas, laintervención humana Eso permite introducir, sindificultades, una dimensión temporal, una perspectiva dinámica y evolutiva.” (TRICART, 1979, p. 36).

Rodrigues (2001) reforça esta idéia quando afirma que a abordagem Geossistêmica trouxe um caráter dinâmico ao estudo da paisagem, tendo em vista que se é possível realizar uma classificação dos geossistemas formando uma série histórica de acordo com o estado em que paisagem se encontrava em períodos distintos, podendo com isso, a realização de prognósticos visando o planejamento territorial; que não deixa de ser o foco desta pesquisa.

Ao estudar as áreas de vulnerabilidade sociais e os riscos naturais de uma localidade deve-se ter em mente a necessidade de se compreender tanto a dinâmica dos elementos naturais que compõem um território, como também os condicionantes sociais que expõem um indivíduo ou grupo de indivíduos a situação de risco. São alguns conceitos fundamentais que foram produzidos por diversos autores ao longo do desenvolvimento desta temática até a atualidade, tais como: Riscos; Perigos; Vulnerabilidade; Desastre; e Catástrofe, são fundamentos dos estudos sobre vulnerabilidade socioambiental.

Para fundamentação deste artigo foram utilizados os conceitos de Risco e Perigo propostos por Veyret (2007) e Smith (2001), respectivamente. Tais autores se enquadram como expoentes do desenvolvimento desta vertente da Geografia, assim como Blaikie et al. (1994), do qual utilizou-se o conceito de vulnerabilidade, em um apanhado conceitual de Susan Cutter (1996).

O risco é uma construção social, está diretamente ligado à concepção da população em relação a algum perigo potencial de causar danos físicos e perdas materiais de grande monta, uma população pode não ter a percepção de que está em risco. O risco é definido por Yvette Veyret 
como sendo a "percepção de um perigo possível, mais ou menos previsível por um grupo social ou por um indivíduo que tenha sido exposto a ele" (VEYRET, 2007, p.24).

De forma simplificada, pode-se considerar o risco vinculado a um acontecimento que pode realizar-se ou não. Contudo, a existência de um risco só se constitui quando há a valorização de algum bem, material ou imaterial, pois não há risco sem a noção de que se pode perder alguma coisa. Portanto, não se pode pensar em risco sem considerar alguém que corre risco, ou seja, a sociedade. (CASTRO; PEIXOTO; RIO, 2005, p. 27).

Portanto, a partir das concepções expostas acima, o Risco socioambiental pode ser conceituado pela seguinte equação: $\mathrm{R}=\mathrm{P} \times \mathrm{V}$, onde: $\mathrm{R}=\mathrm{Risco} ; \mathrm{P}=$ Perigo e $\mathrm{V}=$ Vulnerabilidade.

O termo perigo, comumente é confundido com o risco, como se fossem sinônimos, o que é um equívoco. Perigo seria o evento propriamente dito, como um deslizamento, ou enchente, por exemplo, aquele que é o causador dos danos ou prejuízos. Ou ainda para Veyret "esse termo é, às vezes, empregado também para definir as consequências objetivas de uma álea (evento ou perigo) sobre um indivíduo, um grupo de indivíduos, sobre a organização do território ou sobre o meio ambiente. Fato potencial e objetivo" (VEYRET, 2007, p.24). Assim, para Smith (2001):

O perigo é uma inelutável parte da vida e é uma das componentes do risco. Para o autor, perigo é uma ameaça potencial para as pessoas e seus bens, enquanto risco é a probabilidade da ocorrência de um perigo e de gerar perdas. (apud ALMEIDA, 2010, p.99)

Nos anos 1980 os estudos sobre riscos naturais ("Natural Hazards") passaram a ter foco no fator social da problemática. A vulnerabilidade seria a mensuração da capacidade de cada indivíduo para se preparar, lidar, resistir e possuir habilidade de resiliência quando exposto a um perigo. "A vulnerabilidade mede os impactos danosos do acontecimento sobre os alvos afetados". (Dictionnaire de I'environnement, 1991, apud VEYRET, 2007, p.24). Esta existirá a partir de um perigo em um dado contexto geográfico e social, pois há lugares mais propensos à ocorrência de fenômenos danosos do que outros, bem como indivíduos que por diversos fatores - sociais, políticos, culturais e etc. - possuem menos capacidade de resistência. Devemos levar em consideração também o tempo (cronológico), tendo em vista que a vulnerabilidade pode apresentar sazonalidades, podendo aparecer nas mais variadas escalas temporais. (MARANDOLA e HOGAN, 2006, p.13). Conforme explicado por Lutiane Almeida:

\footnotetext{
O crescimento das desigualdades sociais, da pobreza, da segregação socioespacial advinda com o trinômio capitalismo - industrialização - urbanização, em relação com a consequente degradação do ambiente nas suas diversas facetas, fez surgir em meados dos anos de 1980 uma abordagem teórico-metodológica que procurou enfocar os desastres (naturais ou tecnológicos) do ponto de vista não apenas de seus fatores físicos desencadeantes, mas com base no prisma das populações atingidas. (ALMEIDA, 2010; p 102)
}

Diferente dos conceitos de risco e perigo, o conceito de vulnerabilidade ainda não há um consenso bem definido, havendo assim, múltiplas definições para o que seria vulnerabilidade. Susan Cutter (1996) realizou um apanhado de definições conceituais para o tema entre os anos de 1980 e 
1995. No qual definiu 18 conceitos diferentes de vulnerabilidade. Com esta percepção, a vulnerabilidade é uma condição de suscetibilidade a algum evento potencial de causar danos materiais e físicos à população residente em ambientes de intensa dinâmica natural, como os já citados acima. É preciso determinar o conceito utilizado neste trabalho:

(...) por vulnerabilidade queremos dizer as características de uma pessoa ou grupo em termos de sua capacidade de prever, lidar com, resistir e se recuperar do impacto de um perigo natural. Trata-se de uma combinação de fatores que determinam o grau em que a vida de alguém e os meios de subsistência são postos em risco por um evento discreto e identificável na natureza ou na sociedade (BLAIKIE et al, 1994. Apud CUTTER, 1996).

Neste contexto, a análise de risco ou vulnerabilidade socioambiental proposta neste artigo tem como base a metodologia proposta por Lutiane Almeida (2010), em que este desenvolveu a operacionalização do conceito de vulnerabilidade aplicado às áreas de riscos naturais, exposição a enchentes ou deslizamentos de terra, por exemplo. Neste trabalho, o autor utilizou como recorte espacial a área da bacia do Rio Maranguapinho, região metropolitana de Fortaleza - Ceará, relacionando índices sociais e físico-naturais em sua análise.

Entre Geoprocessamento, Geografia e estudos de risco

Faz-se necessário definir os conceitos inerentes ao geoprocessamento, enquanto disciplina estruturada com conhecimentos e técnicas, sendo bastante utilizado para análises espaciais, o que é foco da Geografia - Ciência que tem como objeto o espaço geográfico. Então geoprocessamento pode ser definido segundo Câmara (2001):

(...) O termo Geoprocessamento denota a disciplina do conhecimento que utiliza técnicas matemáticas e computacionais para o tratamento da informação geográfica e que vem influenciando de maneira crescente as áreas de Cartografia, Análise de Recursos Naturais, Transportes, Comunicações, Energia e Planejamento Urbano e Regional. As ferramentas computacionais para Geoprocessamento, chamadas de Sistemas de Informação Geográfica (GIS), permitem realizar análises complexas, ao integrar dados de diversas fontes e ao criar bancos de dados georreferenciados. Tornam ainda possível automatizar a produção de documentos cartográficos. (CÂMARA e DAVIS, 2001, p.1)

Conforme visto nesta referência, o geoprocessamento é o ramo do conhecimento, em que o autor propõe ser a "Ciência da Geoinformação", como intitulado nesse livro. O GIS em inglês ou SIG (Sistema de Informações Geográficas), em português, versa sobre a ferramenta computacional que facilitou a aplicabilidade e produtividade do geoprocessamento em ambiente digital, com cálculos e análises estatísticas realizadas de maneira muito mais rápida. Além destas análises complexas o SIG também é o local de automação da produção de mapas, em constante evolução ao longo do tempo, onde na atualidade há a busca pelo caráter temporal e processual das análises. 
O geoprocessamento surge a partir das análises geográficas, para suprir a necessidade desta ciência na produção de mapas e estudos diversos sobre o espaço geográfico. Ao longo do desenvolvimento desta ciência o geoprocessamento foi utilizado conforme a concepção das linhas de pensamento geográfico, sendo muito bem definidas as etapas do pensamento geográfico e sua relação com o geoprocessamento, conforme afirma Câmara e Davis (2001):

(i) Geografia Idiográfica (GIS dos anos 80): o conceito-chave é a unicidade da região, expresso através de abstrações como a "unidade-área" (Hartshorne), "unidade de paisagem" (Tricart) e "land-unit" (Zonneveld). A representação computacional associada é o polígono com seus atributos (usualmente expressos numa tabela de um banco de dados relacional) e as técnicas de análise comuns, está o uso da interseção de conjuntos (lógica booleana). (ii) Geografia Quantitativa (GIS de hoje): o conceito-chave é a distribuição espacial do fenômeno de estudo, expressa através de um conjunto de eventos, amostras pontuais, ou dados agregados por área. A representação computacional associada é a superfície (expressa como uma grade regular) e há uma grande ênfase no uso de técnicas de Estatística Espacial e Lógica Nebulosa ("fuzzy") para caracterizar com o uso (respectivamente) da teoria da probabilidade e da teoria da possibilidade as distribuições espaciais. (iii) Geografia Quantitativa (GIS da próxima geração): o conceito-chave são os modelos preditivos com representação espaço-temporal, onde a evolução do fenômeno é expressa através de representação funcional. Para capturar as diferentes relações dinâmicas, as técnicas de Análise deverão incluir modelos multi-escala, que estabeleçam conexões entre fenômenos de macroescala (tipicamente relacionados com fatores econômicos) e fenômenos de microescala (tipicamente associados a transições no uso da terra). (iv) Geografia Crítica (GIS do futuro): aqui, os conceitos-chave incluem o espaço como "sistema de objetos e sistemas de ações" e a oposição entre "espaço de fluxos" e "espaço de lugares". Podemos apenas especular sobre as representações computacionais que serão utilizadas neste contexto, que possivelmente incluam técnicas de Representação de Conhecimento. Nossa hipótese de trabalho é que os GIS do futuro contemplarão representações não-cartográficas do espaço, com uma ênfase no estabelecimento de relações entre os diferentes atores sociais que atuam no espaço. (CÂMARA e DAVIS, 2001, p. 5-13)

Muitas destas ferramentas são utilizadas nos estudos de risco em Geografia. Uma função básica destas análises é o mapeamento de áreas de risco, o que com uso do SIG, utilizando conhecimentos de geoprocessamento e cartografia digital, se torna muito mais produtivo. A partir deste mapeamento básico, com utilização até de GPS portátil, há a fase de análise e sobreposição cartográfica, em que se estabelece o relacionamento entre variáveis de vulnerabilidade social e ambiental. Nesta etapa de sobreposição podem ser utilizadas ferramentas como lógica booleana, que trata da intersecção de conjuntos (ou unidades de área) a partir dos polígonos definidos para ocupação de risco sobrepostos com áreas de ambientalmente frágeis, como campo dunares ou áreas de várzea, definidas com utilização de imagens aéreas e mapeamento de campo.

Também, neste contexto, podem-se utilizar elementos de geoprocessamento de outra geração de SIG, conforme citado por Câmara e Davis, que é inerente à representação computacional 
associada a superfície (expressa como uma grade regular). Esta atividade foi realizada na pesquisa que será apresentada como estudo de caso deste artigo, onde foi feito levantamento de campo em malha regular de pontos com $75 \mathrm{~m}$ de equidistância, no bairro Mãe Luiza, o que teve como produto o mapa de vulnerabilidade social do bairro. Sendo produzido a partir do índice de vulnerabilidade social para cada ponto e sua interpolação em ambiente SIG, o que gerou uma superfície de distribuição do fenômeno para o referido bairro.

Esta atividade traz a medida da incerteza a partir de pontos conhecidos (levantados) a partir do cálculo de estatística espacial por triangulação, gerando um Modelo Número de Terreno (MNT), conforme afirma Câmara e Monteiro (2001, p. 9), "um MNT pode ser definido como um modelo matemático que reproduz uma superfície real a partir de algoritmos e de um conjunto de pontos (x, y), em um referencial qualquer, com atributos denotados de $\mathrm{z}$, que descrevem a variação contínua da superfície".

\section{GEOPROCESSAMENTO APLICADO AOS ESTUDOS DE RISCO EM GEOGRAFIA: ESTUDOS DE CASO}

Vulnerabilidade Socioambiental do Município de Natal, RN, Brasil.

O trabalho em questão foi realizado como dissertação para obtenção do título de mestre em Geografia, de Marysol Dantas de Medeiros, no Programa de Pós-graduação em Geografia da Universidade Federal do Rio Grande do Norte. Este teve como objeto a análise geográfica das áreas de risco do município de Natal, inclusive mapeando novas áreas. Tal como citado anteriormente, ambos os trabalhos aqui expostos têm como base a metodologia de análise de risco socioambiental de Almeida (2010) e Veyret (2007). Trata-se da equação em que o risco (R) seria uma função entre Vulnerabilidade (V) e Perigo ambiental (P). Neste artigo, o trabalho em questão será analisado com ênfase nas técnicas e ferramentas de geoprocessamento utilizados.

Sinteticamente a metodologia de trabalho, para ambas as pesquisas expostas aqui como estudo de caso, tem as seguintes etapas e características. O primeiro momento tem-se a produção do índice de vulnerabilidade social; após esta etapa há a produção do índice de vulnerabilidade físiconatural (ou ambiental), que retrata a exposição da população aos perigos ambientais nos locais identificados; por fim tem-se a sobreposição dos dois índices por meio de técnicas cartográficas em ambiente SIG, compondo um terceiro resultado de análise espacial que é o índice de vulnerabilidade socioambiental exposto em forma de mapa e em banco de dados relacional para diversas aplicações.

Logo no início desta pesquisa se fez uso do geoprocessamento para identificar as áreas de risco já mapeadas pela Defesa Civil Municipal em 2008. Com isso foram obtidos os arquivos 
digitais georreferenciados em formato de camadas vetoriais (shapefile) para uso no software ArcGIS v. 9.3. Da mesma forma foi obtido o arquivo referente aos setores censitários de Natal, no sítio do IBGE - Instituto Brasileiro de Geografia e Estatística - na internet. O que foi utilizado como unidade de área básica para a configuração do mapa de vulnerabilidade social de Natal, que consta da primeira etapa da pesquisa. Assim como confecção dos primeiros mapas, que foram separados por regiões administrativas da cidade com imagem áreas sotopostas visando auxiliar o trabalho de campo.

Na primeira etapa desta pesquisa houve a produção do Índice de Vulnerabilidade Social IVS. Esta se deu com utilização de análise estatística fatorial, para agrupamento das variáveis que representaram condição da vulnerabilidade social em seis fatores. Após esta análise, cada setor censitário de natal, unidade de área básica para o IVS, teve um resultado de IVS, e de cada fator separadamente. Conforme relata a autora Marysol Medeiros (2015).

A construção do Índice de Vulnerabilidade Social incidiu na utilização da técnica de análise multivariada, que agrupa diversas variáveis, na qual resultou na redução das 21 variáveis em apenas 6 fatores, sendo esta técnica chamada Análise Fatorial. A partir desta análise, foram obtidas as estimativas dos fatores para cada setor. Com a sobreposição dos seis fatores foi possível realizar um mapeamento dos setores censitários com maiores índices de vulnerabilidade social na cidade de Natal. A partir da utilização do programa de Geoprocessamento ArcGIS 9.3 foi possível formar grupos que guardam semelhanças quanto a vulnerabilidade social por setores, usando-se o método estatístico Natural Breaks, já que este mostrou resultados mais próximo a realidade. Assim, os dados foram divididos em seis classes que vão desde a vulnerabilidade social muito baixa, abrangendo os setores com os melhores indicadores sociais, à vulnerabilidade social muito alta, representando os setores censitários com os piores indicadores sociais. (MEDEIROS, 2015, p.68)

O resultado desta etapa foi muito elogiado pela equipe acadêmica de avaliação, pois retratou bem a realidade conhecida da cidade, se tornando uma metodologia plausível. A seguir o mapa produzido, onde é retratada espacialmente o resultado do IVS obtido para Natal, com unidade de área básica os setores censitários do IBGE.

Para a segunda etapa da pesquisa, o IVFN - Índice de Vulnerabilidade Físico-natural, a autora utilizou metodologia de Crepani (2001), baseada no conceito de Ecodinâmica de Tricart (1977), o qual propõe que as unidades de paisagem são mais instáveis quanto maior é a morfogênese em relação à pedogênese. Portanto, as unidades seriam mais vulneráveis quanto menos estáveis forem. Para operacionalização desta metodologia fez-se necessário a produção e sobreposição cartográfica de vários mapas temáticos de acordo com aspectos do meio físico. Conforme relata Medeiros (2015).

(...) os mapas elaborados contendo os temas dos diferentes aspectos físicos formam os Planos de Informações temáticos georreferenciados (PI). Dessa maneira, foi 
realizada a análise de vulnerabilidade a partir de cada PI separadamente, para posteriormente, ser realizada a interseção vetorial destes Planos de Informações, tendo como resultado final o mapa com as Unidades Territoriais Básicas (PI UTB), no qual Crepani (2001) define como sendo "uma entidade geográfica que contém atributos ambientais que permitem diferenciá-la de suas vizinhas, ao mesmo tempo em que possui vínculos dinâmicos que a articulam a uma complexa rede integrada por outras unidades territoriais." (CREPANI, 2001; ps. 12 e 13). (MEDEIROS, 2015, p.79)

Para se atribuir os valores de vulnerabilidade a cada unidade territorial é adotada a seguinte equação:

$$
V=\frac{(G+R+S+V g+C)}{5}
$$

Na qual: V: vulnerabilidade; G: vulnerabilidade para o tema geologia; R: vulnerabilidade para o tema geomorfologia; S: vulnerabilidade para o tema pedologia; Vg: vulnerabilidade para o tema vegetação. $\mathbf{C}$ : vulnerabilidade para o tema clima.

Percebe-se aí que esta metodologia está diretamente ligada às técnicas cartográficas inerentes ao geoprocessamento, com utilização do ambiente SIG para operacionalização desta fórmula. O que se dá a partir da sobreposição dos planos de informações, que são cada um dos mapas dos aspectos inerentes ao meio físico como Clima, Geologia e Solos entre outros.

Para tanto, utilizou-se a ferramenta Field Calculator, do programa SIG Arcgis 9.3para obtenção da média aritmética da interseção dos polígonos contendo dados dos cinco Planos de Informações. Em uma típica ferramenta de análise espacial com utilização de fórmulas matemáticas como média aritmética simples para dados do tipo raster (imagem), mas que poderia também utilizar-se de lógica booleana em se tratando de dados vetoriais (shapefile). Estas ferramentas condizem com a corrente de pensamento da Geografia quantitativa e ideográfica, respectivamente, conforme supracitado com base em Câmara e Davis (2001). O mapa resultante desta etapa da pesquisa pode ser analisado na figura 02. Assim como o resultante da primeira etapa de vulnerabilidade social. 


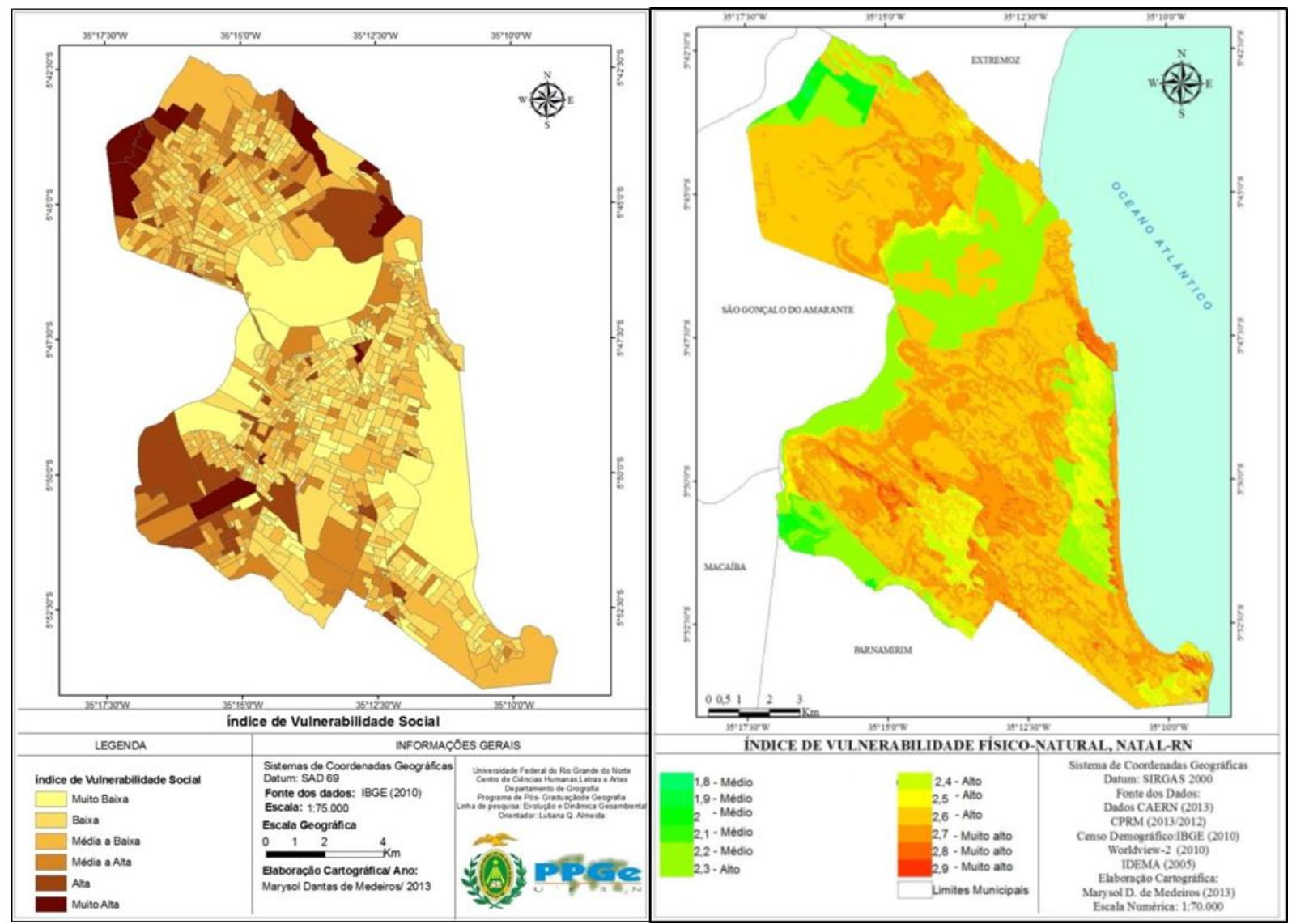

Figura 02. Espacialização do Índice de Vulnerabilidade Social à esquerda. Espacialização do Índice de Vulnerabilidade Ambiental à direita. Fonte: MEDEIROS, 2014.

Por fim, como produto final desta pesquisa, a autora fez uma análise dos dois índices anteriores: IVS - para características de Vulnerabilidade Social; e IVFN - para características de exposição físico-natural ou ambiental. Isto foi possível a partir da utilização da ferramenta Field Calculator do software ArcGis 9.3 e a partir dos princípios da lógica booleana ${ }^{1}$ com o uso da operação AND ou E, foi possível a realização da álgebra dos mapas temáticos com cruzamento dos polígonos.

Esta etapa, com utilização desta ferramenta com tal tipo de lógica, basicamente, relaciona os polígonos dos dois planos de informações, sobrepondo-os e gerando outro plano de informação com o resultado deste relacionamento. Este produto tem sua classificação a partir do agrupamento das 3 classes de IVFN com as 6 classes de IVS, em uma matriz de correlação. Em que, por exemplo, onde houver nível 6 de IVS com nível 3 de IVFN terá IVSA - Índice de Vulnerabilidade Ambiental muito alto. E assim sucessivamente. O resultado desta análise pode ser visto no mapa, representado na figura 03.

\footnotetext{
${ }^{1}$ A lógica booleana, ou Álgebra booleana, é um sistema de lógica matemática criada pelo matemático inglês George Boole (daí a origem da denominação). É utilizada para criar regras lógicas ou expressões usadas para analisar, selecionar e processar dados.
} 


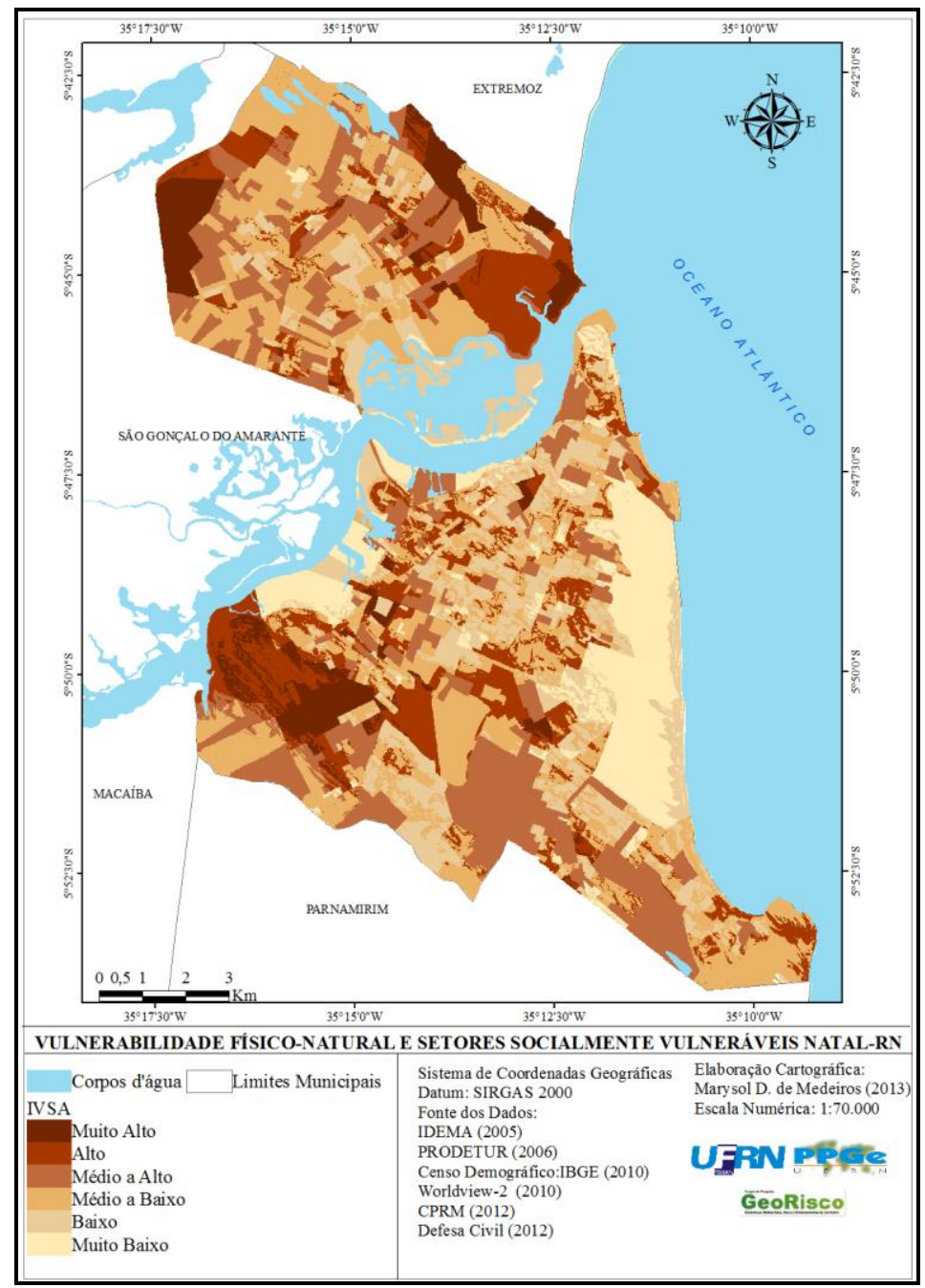

Figura 03. Mapa de vulnerabilidade socioambiental. Fonte: Elaborado por Marysol Medeiros a partir de dados do IDEMA (2005), PRODETUR (2006), IBGE (2010), Imagens Worldview-2 (2010), CPRM (2012) e Defesa Civil Municipal (2012).

A sobreposição dos índices de vulnerabilidade social e ambiental resultou no índice de vulnerabilidade socioambiental. Esta metodologia apresentou resultados satisfatórios, tendo em vista que muitas áreas da cidade com alta vulnerabilidade socioambiental foram confirmadas quando realizados os campos de reconhecimento da área. Como podem ser observadas na figura 03, diversas áreas da cidade já conhecidas por exibir episódios recorrentes de alagamentos, deslizamentos ou inundações obtiveram valores de vulnerabilidade socioambiental elevada. Todavia, áreas precárias de infraestrutura urbana e com população mais carente também trouxeram altos valores de vulnerabilidade socioambiental. 
Vulnerabilidade Socioambiental no Bairro Mãe Luiza, Natal - RN/Brasil.

O objeto desta pesquisa residiu na elaboração de indicadores socioambientais de risco de desastres, presente em áreas de ocupação humana precária associada à intensa dinâmica ambiental, na perspectiva dos estudos sobre o tema em Geografia. Definiu-se como área de estudo o bairro Mãe Luiza, em Natal, capital do Estado do Rio Grande do Norte (Figura 01). O local foi escolhido como tal por historicamente apresentar diversas condições de vulnerabilidade e exposição ao risco de desastres.

Também houve pesquisa em acervo digital de órgãos de gestão territorial urbana e ambiental, como a SEMURB - Secretaria de Meio Ambiente e Urbanismo de Natal; IDEMA Instituto do Desenvolvimento Sustentável do Rio Grande do Norte; e CPRM - Companhia de Pesquisa em Recursos Minerais do Brasil. Deste modo se adquiriu arquivos digitais em formato vetorial (shapefile) inerente ao ambiente SIG, em software computacional ArcGIS v. 10.0.

A metodologia de trabalho, assim como a pesquisa citada anteriormente, foi dividida em duas etapas paralelas, que se relacionam espacialmente no território do bairro, com a análise de risco socioambiental ( $3^{\mathrm{a}}$ Etapa). A primeira etapa versa sobre o IVS - Índice de Vulnerabilidade Social; e segunda etapa o IEMM - Índice de Exposição aos Movimentos de Massa. Com estas etapas concluídas, realizou-se análise integrada, com auxílio de técnicas de sobreposição cartográficas (Overlay) e classificação por lógica booleana. Deste modo, foi produzido (e espacializado em mapa) o Índice de Vulnerabilidade Socioambiental para o local de estudo.

Na primeira etapa, na produção do IVS, foi utilizada técnica de amostragem em malha regular de pontos, para confecção de uma superfície regular da mesma forma do MNT citado anteriormente. Esta técnica advém do conhecimento de geoestatística (estatística espacial), muito utilizado em geologia e mineração para pesquisa mineral ou cubagem de jazidas, e é utilizada para estimar valores para regiões desconhecidas a partir de pontos amostrados em locais vizinhos ou próximos.

Optou-se então, pelo levantamento que foi disposto na área de estudo com uma malha de amostragem com equidistância de $75 \mathrm{~m}$ entre os pontos em Mãe Luiza. Em cada ponto (ou nó) desta malha, foi aplicado questionário por unidade domiciliar. Este dado, consequentemente, será representativo de seu entorno correspondente. Cada ponto foi obtido em GPS portátil modelo Garmim Vista-cx, com erro de precisão médio de 10 metros. A partir desse procedimento pode-se nos localizar e coletar os dados em todos os pontos dispostos nos limites do Bairro.

O produto final de toda a análise desta etapa do trabalho resultou no IVS - Índice de Vulnerabilidade Social, espacializado em ambiente S.I.G. - Sistema de Informações Geográficas, 
com uso do Software computacional ArcGIS Versão 10.0. Sendo obtido a partir da interpolação dos valores pontuais, com utilização da ferramenta de geoprocessamento Spatial analyst (Análise Espacial) através do método Natural Neighbor (Vizinho Natural). Esta ferramenta é um método estimador geoestatístico, que se baseia na interpolação de pontos amostrados para estimar pontos não amostrados. Isto é possível, geometricamente, a partir da triangulação entre pontos amostrados, onde cada vértice gerado é um novo ponto de acordo com a média entre os pontos amostrados, ponderada pela distância entre eles.

Em consequência, para obtenção do resultado, utilizou-se o método de classificação natural breaks (quebras naturais), desenvolvido pelo cartógrafo americano George Jenks (1967), muito utilizado em Cartografia para a produção de mapas coropléticos. O método reduz o desvio padrão dentro das classes e maximiza sua variância, visando a otimização da visualização dos mapas. $\mathrm{O}$ produto resultante desta etapa do trabalho foi espacializado em mapa contendo cinco níveis ou classes: Nível 1: Vulnerabilidade Social Baixa; Nível 2: Vulnerabilidade Social Média; Nível 3: Vulnerabilidade Social Média a Alta; Nível 4: Vulnerabilidade Social Alta; e Nível 5: Vulnerabilidade Social Muito Alta.

A segunda etapa deste trabalho consistiu na determinação do IEMM - Índice de Exposição aos Movimentos de Massa, o qual se baseia no trabalho realizado por Guerra et. al (2009). O trabalho consistiu em estudo realizado para a região serrana do Estado do Rio de Janeiro, onde sazonalmente há ocorrência de desastres socioambientais (deslizamento), com perdas físicas e danos ao patrimônio público e privado de grande monta.

O Índice de Exposição aos Movimentos de Massa (IEMM) produzido teve como malha amostral as unidades geoambientais do bairro. A partir destas características, foi aplicado um formulário táctil-visual. É preciso ressaltar que, conforme citado neste item, as variáveis, por se tratar de local antropizado, levam em consideração as mudanças realizadas pelo Homem em sua estabilização no bairro, não somente características ambientais naturais, sem a influência da sociedade. O que resultou também em cinco classes deste índice.

Após a exposição dos resultados dos dois índices e seus respectivos mapas, foi feita a análise do IVSA - Índice de Vulnerabilidade Socioambiental, que foi o produto final desta pesquisa. Esta análise foi realizada a partir de técnicas matemáticas em ambiente SIG, com uso de lógica booleana, tal como a pesquisa citada anteriormente. A qual combina os polígonos dos dois índices por correlação espacial.

A figura 04 mostra como foi feita a correlação entre IEMM e IVS para classificação do IVSA. Ao final tem-se uma matriz simplificada, com a correlação dos valores para obtenção do índice relacionado à Vulnerabilidade Socioambiental. Este exercício resultou em cinco (5) classes, 
assim como os índices citados anteriormente. As quais foram elencadas, respectivamente, como: 1) Muito Baixa; 2) Baixa; 3) Média; 4) Alta; 5) Muito Alta.

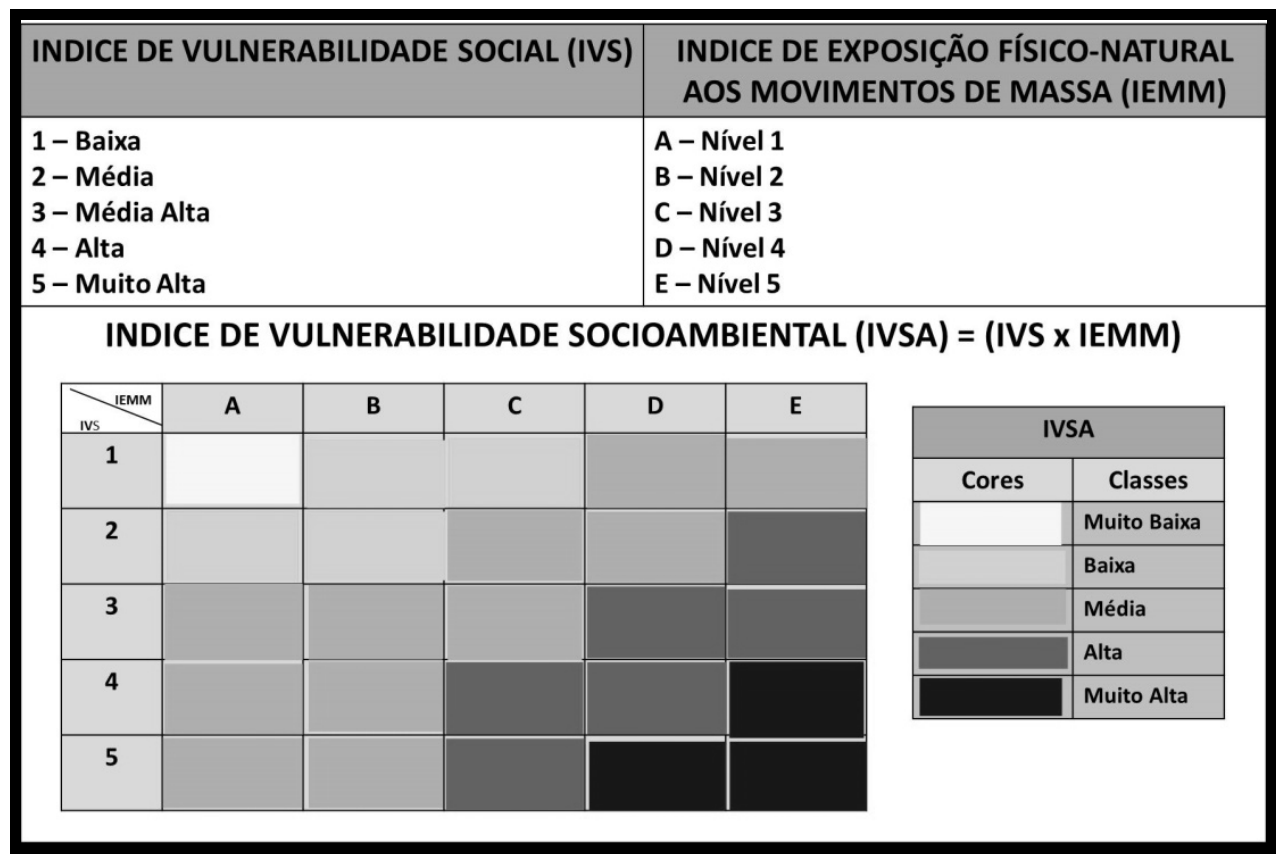

Figura 04. Metodologia para obtenção e classificação do IVSA. Fonte: MACEDO (2015), baseado em Almeida (2010).

Os resultados foram obtidos após a sobreposição cartográfica dos dois índices anteriores, com utilização de lógica booleana. Esta lógica foi utilizada para sobreposição cartográfica, em que as áreas de IVS e IEMM foram relacionadas, seguindo o padrão exposto na figura 04. A figura 05 mostra o resultado dos três índices desta pesquisa e seus respectivos mapas, culminando com o IVSA que é o produto da correlação entre os dois primeiros para o bairro Mãe Luiza. As áreas mais escuras correspondem à sobreposição de elevado nível de IEMM com alto e muito alto nível de IVS. Cada classe dos índices anteriores representou um polígono no mapa, com o valor da classe correspondente, que foram correlacionados para produção do índice geral. A partir dessa matriz de relacionamento (Figura 04), cada resultado da sobreposição foi enquadrado em uma classe de IVSA. 


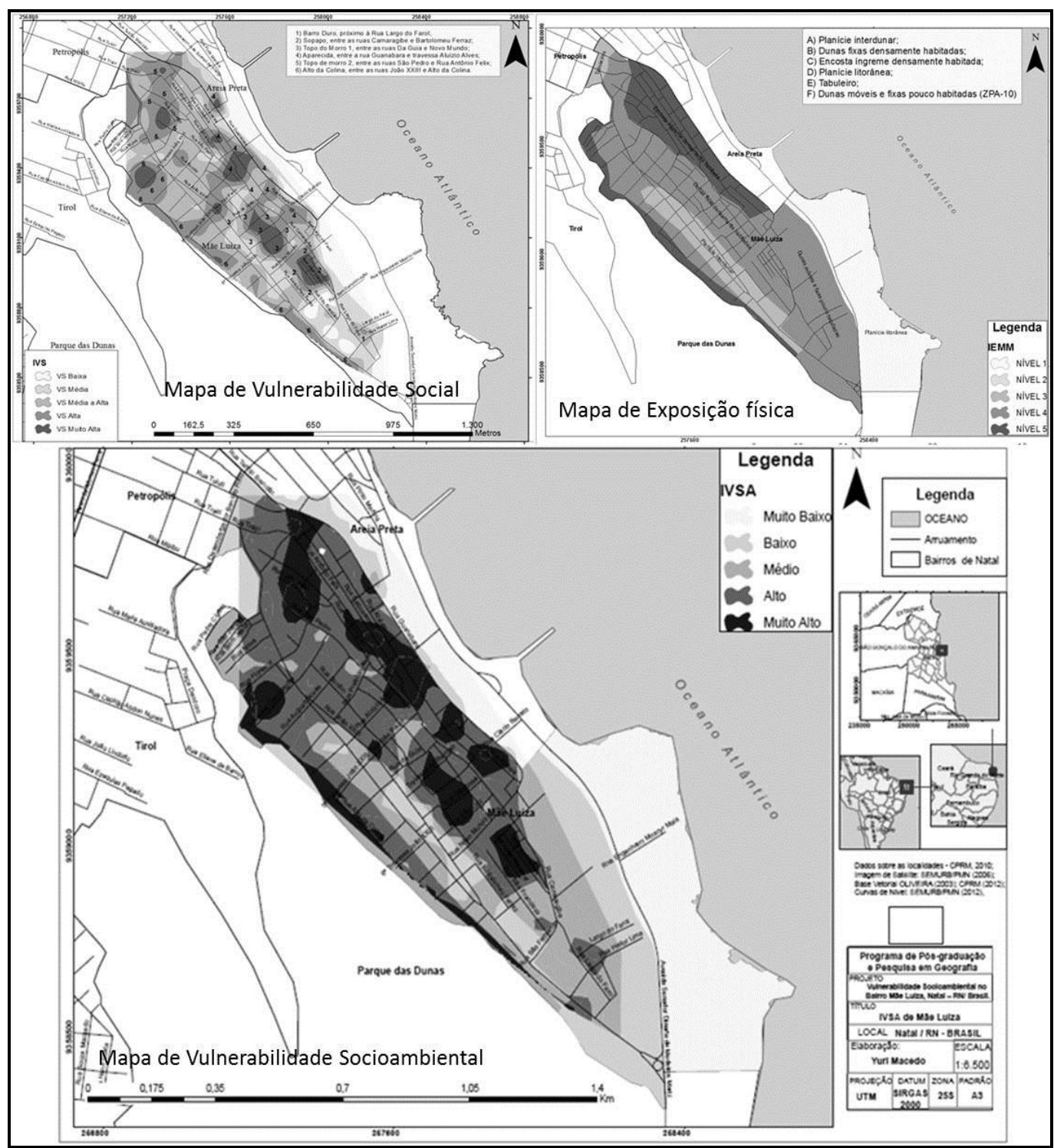

Figura 05. Mapas de Vulnerabilidade Social; de Exposição aos Movimentos de Massa; e Mapa de Vulnerabilidade Socioambiental. Fonte: MACEDO (2015), baseado em Almeida (2010).

A partir da análise do mapa foi possível concluir que há, em Mãe Luiza, pelo menos sete (7) áreas com Muito Alto IVSA. Somente este dado já acrescenta ao estudo de risco no bairro, pois o PMRR - Plano Municipal de Redução do Risco - material de referência para Defesa Civil Municipal (DCM) - propõe quatro áreas de risco apenas. Com os resultados encontrados, podem-se propor duas novas áreas de risco em locais antes não identificados ou detalhados pela DCM.

A partir do Mapa de Vulnerabilidade Socioambiental do bairro Mãe Luiza, pode-se identificar que, todas as áreas de alta vulnerabilidade social, já identificadas, após o cruzamento com o IEMM, obtiveram Muito Alta vulnerabilidade socioambiental também. Com esse resultado pode-se concluir que há correlação direta entre áreas de alta vulnerabilidade social com alta exposição a perigos ambientais. Contudo, ao mesmo tempo, conclui-se que estas áreas de risco são desvalorizadas e se oferecem para ocupação de famílias ou grupo de pessoas com baixo poder 
aquisitivo em condição de vulnerabilidade social. Ou que o processo de ocupação no bairro ocorreu de forma a assentar pessoas ou grupos de menor VS nas áreas mais seguras, restando às residências mais perigosas para os mais vulneráveis socialmente.

Estas duas hipóteses são confrontantes em estudos de risco socioambiental. Nesta pesquisa, seguindo a corrente de pensamento que embasou toda análise, optou-se pela percepção que as populações com maior VS são levadas a ocuparem locais perigosos por estes serem desvalorizados, se oferecendo, portanto, à ocupação por tais populações. O bairro Mãe Luiza, como exposto, é conhecido como de alta VS, porém esta configuração não se faz de maneira homogênea em toda extensão do bairro. Em busca dessas diferenciações que se estruturou esta análise, objetivo exitoso após análise dos resultados.

\section{CONSIDERAÇÕES FINAIS}

De acordo com o que ser propôs este artigo, os estudos de risco e vulnerabilidade, em Geografia especificamente, assim como em outras ciências que estudam o tema (Geologia ou Engenharia Civil), utilizam ferramentas de geoprocessamento como fundamental às suas análises. Com os estudos de caso levantados aqui, percebe-se que o geoprocessamento, a partir do sistema computacional que operacionaliza suas técnicas matemáticas e espaciais, o SIG, é a base para que as análises de sobreposição cartográfica e análise espacial, fundamentais aos estudos de risco, aconteçam. Conforme foi mostrado anteriormente, os estudos desta temática sobrepõem e correlacionam variáveis sociais e ambientais (ou naturais). Com isso se torna eminentemente geográfica, pois esta ciência tem como objeto o "conjunto indissociável de objetos de ações" (SANTOS, 1996, p. 63), que é a definição para o próprio espaço geográfico. Portanto, as variáveis sociais analisadas seriam inerentes às ações; e as variáveis ambientais aos objetos. Desta maneira sua correlação final, neste caso a análise socioambiental, seria nada mais do que uma análise espacial, quando posta â guisa dos conhecimentos geográficos.

Deste modo o geoprocessamento é fundamental não somente aos estudos de risco como à Geografia como um todo. Podendo ser utilizado por diversos ramos desta ciência, a partir de sua análise espacial com grande nível de complexidade. Porém é preciso pontuar suas limitações, principalmente quando se trata das análises inerentes à corrente mais moderna da Geografia, encabeçada por Milton Santos, que é a chamada Geografia Crítica, conforme citado anteriormente.

E é neste caminho que este ramo do conhecimento geográfico, o geoprocessamento, deve caminhar no futuro. Com análises cada vez mais relacionais e complexas, visando atender os 
questionamentos geográficos propostos pela sociedade que tece uma rede de ações, gradativamente, mais complexa.

\section{REFERÊNCIAS BIBLIOGRÁFICAS}

ALMEIDA, L. Q. de. Vulnerabilidades Socioambientais de Rios Urbanos: Bacia Hidrográfica do Rio Maranguapinho, Região Metropolitana de Fortaleza, Ceará. 2010. 278 f. Tese (Doutorado) - Departamento de Instituto de Geociências e Ciências Exatas, Universidade Estadual Paulista, Rio Claro, 2010.

CÂMARA, G.; DAVIS, C.; MONTEIRO, A. M. V. Introdução à Ciência da Geoinformação. São José dos Campos, INPE, 2001.

CAStro, A. L. C. Glossário de Defesa Civil: Estudo de Risco e Medicina de Desastres. Ministério do Planejamento e Orçamento. Brasília. 1998, 283p.

CUTTER, S. L. Vulnerability to environmental hazards. Progress in Human Geography, v. 20, n. 4, p. 529-539, 1996.

DNV MANAGE RISCK. Risk - A Word From Ancient Greece: Em Debater E Analisar O Aspecto Do Risco, Você Já Se Perguntou Sobre A Origem Do Termo "Risco"?.Disponívelem: <http://www.dnv.com/focus/risk_ management/more_ information/risk_origin/>. Acesso em: 06 Jun. 2015.

GUERRA, A. J. T et. Al.. Criação de um sistema de previsão e alerta de riscos a deslizamentos e enchentes, visando minimizar os impactos socioambientais no bairro Quitandinha, Bacia do Rio Piabanha (Afluente Do Paraíba Do Sul), Município de Petrópolis-RJ. Anais II Seminário de Recursos Hídricos da Bacia Hidrográfica do Paraíba do Sul: Recuperação de Áreas Degradadas, Serviços Ambientais e Sustentabilidade, Taubaté, Brasil, 09-11 dezembro 2009, IPABHi, p. 785824.

IBGE - Instituto Brasileiro de Geografia e Estatística. Censo demográfico 2010 - Natal. Rio de Janeiro, 2013.

OLIVEIRA, F. F. G. de. Caracterização e diagnóstico de impactos ambientais em Natal/RN com apoio de geoprocessamento. Dissertação (Mestrado em Geografia) - UFRN, Natal, 2003.

SANTOS, M. A Natureza do Espaço: Técnica e Tempo. Razão e Emoção. São Paulo, Hucitec, 1996.

VEYRET, Y. Os Riscos: O Homem como agressor e vítima do meio ambiente. São Paulo: Contexto, 2007.

\section{AGRADECIMENTOS}

À Universidade Federal do Rio Grande do Norte - UFRN, pelo apoio técnico e científico para realização deste trabalho. Em especial ao Programa de Pós-graduação em Geografia PPGE/UFRN, seus professores e funcionários, os quais foram fundamentais para construção do 
conhecimento neste processo que perpassou o nível de especialização lato senso, mestrado e doutoramento. Muito obrigado.

Recebido em: 20/06/2018

Aceito para publicação em: 29/07/2018 